Article

\title{
New Lens to Reveal the Street Interface. A Morphological-Visual Perception Methodological Contribution for Decoding the Public/Private Edge of Arterial Streets
}

\author{
Nawaf Saeed Al Mushayt *(D), Francesca Dal Cin (1) and Sérgio Barreiros Proença \\ formaurbis LAB, CIAUD-Research Centre for Architecture Urbanism and Design, Lisbon School of Architecture, \\ Universidade de Lisboa, 1349-063 Lisboa, Portugal; francescadalcin@fa.ulisboa.pt (F.D.C.); \\ sergioproenca@edu.ulisboa.pt (S.B.P.) \\ * Correspondence: nmushayt@edu.ulisboa.pt
}

check for

updates

Citation: Al Mushayt, N.S.; Dal Cin, F.; Barreiros Proença, S. New Lens to Reveal the Street Interface. A Morphological-Visual Perception Methodological Contribution for Decoding the Public/Private Edge of Arterial Streets. Sustainability 2021, 13 11442. https://doi.org/10.3390/ su132011442

Academic Editors: Theo Arentze and Pauline Van den Berg

Received: 29 August 2021

Accepted: 13 October 2021

Published: 16 October 2021

Publisher's Note: MDPI stays neutral with regard to jurisdictional claims in published maps and institutional affiliations.

Copyright: (c) 2021 by the authors. Licensee MDPI, Basel, Switzerland. This article is an open access article distributed under the terms and conditions of the Creative Commons Attribution (CC BY) license (https:// creativecommons.org/licenses/by/ $4.0 /)$.

\begin{abstract}
Streets have different forms that are not defined only by their partitions, furniture, and width, but also by their edges as vital features of their spatiality. The relationship between a street and a building impacts the street interface configurations, resulting in various topological characteristics. Thus, the street interface is a physical entity that is produced by the interrelationship between urban morphological elements (street and building), and the way it is formed and used affects the livability of the street. The methods used in the current study contribute to an empirical urban morphologicalvisual cognitive investigation of arterial street interface configurations, particularly on the ground floor level, to assess potential relations between variations in the physical configurations that influence pedestrian visual perception using mobile eye-tracking glasses. In conclusion, this study contributes to research into developing a spatial framework for arterial street liveability, addressing the pilot case study of Avenida da República in Lisbon.
\end{abstract}

Keywords: street interface; urban morphology; street morphology; street livability; visual perception; eye-tracking; participation

\section{Introduction}

Cities are complex urban systems [1], which have long been perceived as significant in contributing to livability [2-6]. Complexity in urban design primarily refers to various notions that indicate the components' complexity in all their varying facets, as in the case of the streets [7-10]. Streets are places of great economic and social potential, where human interaction and exchange occurs. They are vital urban spaces [11] that connect the different layers of a city. The street constitutes a shared space; its edges may comprise vertical architectural elements that act as the interface between public and private spaces, particularly on the ground floor level.

The arterial street is the backbone and a crucial component of an urban area's formation. As a linear structure, this typology of street presents dynamics that reflect the new dynamics of social life. It permits essential movement in the urban surroundings. Moreover, this urban space enhances public life, promotes economic growth, and expands urbanity [12].

Aiming at arterial street livability raises the proposition that street livability is a complex concept, directly affected by the street's physical features [13-15] and social and cultural aspects [16-19]. These approaches indicate the value of physical form related to social processes in shaping the complexity of streets' livability. Thus, a livable street is a healthy, vibrant, and socially active place that drives urban vitality and provides the desired setting for everyday urban life, where people and all their activities are the focal points. Consequently, we may infer that the livability of arterial streets is associated with 
their interfaces, this being one of the main defining characteristics of street livability. Gehl (1987) stated that a living city is one in which the buildings' interior spaces complement the outer domain, depending on the edge between the public and private [20]. Additionally, Jacobs (1995) defined great streets as having boundaries that keep the eyes on the street while raising them to more pleasant and healthy places [14].

Gehl (2005) [21] described the historical relationship between streets and buildings, wherein towns emerged due to the exchange between travelers along pathways and vendors in their wayside booths. However, the exchange zone between pathways and wayside booths has remained crucial in shaping the urban form [21]. In this context, the buildings' ground floors along the street are crucial, as they offer dynamism, memories, and cultural values, when architecture is set as the street interface. The street interface can refer to social and leisure places, as well as environments that show the contradictions, expressions, and ways of life of a society [22].

The term street interface refers to the spaces between urban and architectural dimensions on the ground floors of buildings forming collective spaces. As a public space, the street is composed of a horizontal plane, delimited by two vertical planes acting as edges or boundaries, which can include interfaces as part of the building façade on the ground floor. Street interfaces, at eye level, play a significant role in shaping pedestrian experience, as argued by Glaser et al. [23], who stated that "the ground floor maybe only $10 \%$ of a building, but it determines $90 \%$ of the building's contribution to the experience of the environment." (p. 12). However, it is no less common to observe urban limits being defined only through physical barriers, as an edge. These are relevant to the city as part of its urban experience, as they that raise various potentials.

The street interface can be defined based on several factors, including the urban context, use, and configuration. Many authors have discussed the notion of the street interface $[14,17,21,24-29]$. They variously define the space between private and public spaces as a public/private boundary, an edge, betwixt, a threshold, a soft edge, a liminal space, and an interface. In this study, we chose to analyze the composition of the street interface defined as a physical and social entity that falls into conditions of betweenness in relation to other dominant spaces (the street and the buildings), which may create or deny potential social and visual interactions.

Further, several urban theories and studies have emphasized the predominant significance of pedestrians' experience at eye-level, where pedestrian movement, occupation, and interaction occur [23]. However, the human dimension concerning the street interface and how it influences pedestrians' visual perception has been overlooked. The creation of street interface configurations integrated with pedestrians' visual perception remains limited and is rarely analyzed quantitatively. Nowadays, the users' experiences and perceptions are estimated based on intuition, observation, or surveys. In this regard, the current study addresses this gap quantitatively, based on measurable mathematical evidence, offering opportunities to unfold the street interface's configurations in relation to pedestrians' visual perception.

The current study aims to decode how various types of street interface configurations influence pedestrians' visual interactions and, in turn, the street's livability by engaging pedestrians as the main users of the street. The current investigation uses mobile eyetracking glasses to analyze visual perception in a pilot study of Avenida da República, Lisbon (Portugal). The research attempts to answer the question: what are the most important variables of street interface configurations that influence pedestrians' visual perception?

By building on previous research that has demonstrated the value of active street frontages, street interface typology, and mobile eye-tracking glasses, it was anticipated that permeable and accessible configurations influence pedestrians' visual interactions with the street interface $[14,21,27,30-33]$. We argue that the current investigation provides an opportunity to determine whether public life occurs more actively when the interfaces are visually and physically permeable, compared to other variables. Thus, considering the morphological interpretation integrated with the pedestrians' visual perceptions using 
mobile eye-tracking glasses provides a deeper understanding of the street interface's physical-visual perceptual interrelationship. We consider that in the methodology of analysis outlined in this research, where the urban morphological approach is combined with the eye-tracking analysis approach, it is possible to decode the qualities of public space that are essential to building a spatial framework for liveability, going further than simple data collection.

\section{The Configurations of the Street Interface}

The study of urban morphology has contributed to reading the built environment and identifying its fundamental urban elements: the building, the plot, and the street [34,35]. The study of how these components overlap is critical in urban design, planning, and architecture. The urban spatial relation between the street and dwellings, on a micromorphological scale, creates collective spaces with various social functions. These intermediate spaces are considered a case for study by themselves, and they can be decoded in different ways.

Gehl classified the street interface according to the pedestrian's perspective, varying from soft to hard edges to tackle blank limits. Soft edges represent social, permeable, and active ground floors, while hard edges are antisocial and impermeable [20]. Gehl, Kaefer, and Reigstad [21] have further incorporated indicators including scale and rhythm, transparency, appeal to many senses, texture and details, diversity, and vertical façade rhythms.

Bobić [30] introduced a new interface classification that is based on the scope of the complex phenomenon of urbanity. He proposed a topological classification based on the interrelation between private and public spaces as the primary variable from the standpoint of the public realm wherein urbanity occurs. Bobić's classification includes the interface's spatial, visual, and psychological variables, and goes beyond the interface to analyze the spaces in between [30]. The classification includes transparency, setback, and behavior as the principles of design quality.

Dovey and Wood [27] developed more comprehensive detailed typologies of the street interface, which are typical forms of connectivity between private and public spaces. These typologies aim to map the types of street interface and their relationship to the different social and economic exchange circuits. The study introduced four primary variables in characterizing street interface. The first type, accessible/inaccessible, refers to the degree of accessibility between the public/private dominions. Second, direct/setback refers to the entry type of the private space, which creates an interstitial space between the two realms. Third, opaque/transparent is related to the visual communication from public space into private space, where visual connection is significant in commercial and social exchange. Fourth, car/pedestrian, which indicates the mode of access, either by car or foot [27]. In this way, the street interface is a connector between two domains both visually and physically. It connects people to places, people to each other, consumers to products, streets to buildings, and public space to private space.

Kamalipour [31] suggested a similar typological framework based on accessibility and proximity as the two main variables. The proposal draws interrelationships between two variables to create six typological interfaces-adjacent/impermeable, adjacent/accessible, adjacent/porous, distant/impermeable, distant/accessible, and distant porous. The study provides an understanding of the potential configurations of different interfaces based on accessibility and proximity [31].

The review of interface typologies provides an understanding of the most common variables: permeability, proximity, access mode, and interface geometry. In this regard, the spatial variables can present various interface configurations that may affect the users' perception of the place. They also present a specific message to the street users, which can facilitate the physical and visual communication between the two realms, proffering either invitation and social interaction or closure and isolation. Thus, defining the configurations of the street interface in relation to pedestrians' visual perception offer insight into the processes of a positive or negative pedestrian experience, and in turn, the street livability. 
Nevertheless, there is a lack of empirical research that sets out a morphological code or method to categorize street interfaces concerning public life and visual perception.

\subsection{Pedestrians' Visual Perception}

The city's physical structure represents a complex set of urban elements, each one of which has a particular morphological character determined by several factors. Understanding these elements and how individuals perceive them or understand their physical features is essential in shaping a livable built environment, as we both influence the surrounding built environment and are influenced by it. Perception refers to the various senses that allow individuals to experience the world: the link between people and their environment [36].

Visual perception of the surrounding built environment is the process of understanding and responding to external attractions that influence behavior [36]. Visual perception of the environment is an essential aspect of understanding public life that results from the interaction between individuals and the city. The interaction is dominantly achieved by visual perception, whereby perception is the origin of each attitude towards the city [37].

Lynch [11] stated five image elements to organize cities: paths, edges, nodes, districts, and landmarks. His work offered in-depth design knowledge and an understanding of the urban form, consisting of physical and psychological elements represented on maps as symbols. The physical elements of Lynch's theory refer to the perceptual form of the city in this interaction with its perceivers. He emphasized the image by considering visual quality, focusing on four elements: legibility, image, identity, and imageability [11].

In contrast to Lynch's imageability concept, which concentrates on urban elements that pedestrians perceive, Cullen [38] studied their characteristics, scales, and complexity. Cullen presented serial visions that analyze a sequence of images within pedestrians' eyelevel views, using sketches and photographs to describe the urban design's aesthetics [38]. Therefore, people's behavior is based on their reading of the environment, and thus visual perception must be understood in order to study public life.

Donald Appleyard's [39] work The view from the Road focused on the visual requirements of the potential aesthetics of urban highways. The study addressed American cities' visual formlessness and argued that highways could contribute to the American urban landscape's visual perception. Their experimentation investigated the problem of designing visual sequences from the perspective of the driver and passengers [39]. The empirical works of Lynch, Cullen, and Appleyard et al. emphasized the importance of studying humans' visual perception from users' perspectives in order to evaluate the environment. For decades, many researchers and studies have been influenced by these works, including [37,40,41].

People tend to act according to their reading of the built environment's cues, whereby the complex system of a city is based on these relations and interactions with its elements [36]. The reciprocal relationship between people and cities is part of constituting livability, as the built environment has the ability to encourage social activities and create certain types of behavior, particularly in public spaces, including streets [20]. These spaces have an intimate relationship with their users, as the users spend a vast majority of their day-to-day life interacting with the urban environment [42].

As a linear center, the arterial street comprises a series of relationships and interactions between the street's physical components and people. The street's physical form plays a critical role in enhancing the users' experience, whereby the psychological experience and pedestrians' activities are the products of the street form's visual perception.

The configuration of built environments can affect individuals in different ways, including mental health [43] and daily experiences [44]. Therefore, the study of street morphology requires an investigation into visual relations and dialogue, particularly regarding the scale of interaction on the edges of the public space. The visual perception of the arterial street is essential, as it represents a critical part of the urban structure and participates in the city's experiential and visual quality. 


\subsection{Eye-Tracking System}

Eye-tracking studies have a long history of helping to understand the relations between the brain and the visual system, and the first study was in the late 1800s [45]. The studies were expensive and complicated due to the limitations of tools and techniques. The improvement of systems that use eye movement recordings led to improvements in eye-tracking studies. However, to researchers at that time, eye-tracking was still primitive, making it impossible to examine the real world. The evolution in the 1960s and 1970s offered possibilities for further uses and analyses of eye-tracking systems. In the late 1990s, the birth of the new generation of eye trackers brought about the modern-day system, which has opened up new opportunities to move out of the academic arena and into commercial use [46]. However, it is essential to underline that most eye-tracking experiments have been carried out in controlled laboratory settings, which sometimes lead to inconsistent results [47].

The eye-tracking methodology offers opportunities to perform eye-related studies [48]. It is a tool that measures gaze patterns, including fixations and saccades points, and how long a person looks at a defined point. Additionally, eye-tracking defines eye movements, pupil dilation, and the number of blinks [49]. Fixations and saccades are considered the main matrix to measure the eye movements that draw out gaze patterns. Fixations are the period for which the eye is kept aligned on a specific area of the visual field, allowing for visual processing and the encoding of information in memory. Saccades are considered the eye's rapid movements, which help us gain a sense of what we are looking at $[50,51]$. An eye tracker provides a highly accurate representation and understanding of three attributes-location, duration and movement-which comprise an individual's eye movement behavior [45].

Eye-tracking offers various methods to observe the eye's position, helping us understand where an individual is looking in order to study cognitive processes and evaluate user experience (UX). It is a critical methodology for every domain in which people interact, and even those that users cannot describe, such as visual perception [46]. Eye-tracking has become an established research tool that empowers researchers to study human cognition and behavior quantitatively [52], aspects that were absent in Cullen's and Appleyard's sketches and film recordings. One of the main advantages of eye-tracking is that it can be used in a broad range of research interests. Many psychological disciplines, medical fields and marketing studies have employed eye-tracking as an experimental tool $[45,53-56]$.

Technological innovations in data science have made it increasingly possible to measure human experience in architectural spaces with different tools [57]. The new age that we live in offers multiple tools that contribute to our understanding of the influence of architecture and urbanism on many aspects, including social, mental, and physical health [32,52]. Technological innovations in data science have made it increasingly possible to measure the visual perception of space and the function of architecture within it [58]. Additionally, an eye-tracking system has been applied to measure the impact of architectural design features on users' experience in a laboratory-based investigation [59].

In the field of urbanism, a number of recent urban studies used eye-tracking as a research method, either in laboratory-based investigations or in outdoor environments [60-62]. The new hybrid field of neuroscience and urbanism provides insight for studying inhabitants' visual experiences and their perception of the streets and street edges. The work of Simpson et al. (2018) [33] provided empirical insight into pedestrians' visual engagement with different street AOIs using a mobile eye-tracking system, while Spanjar and Suurenbroek's [63] laboratory-based exploratory research focused on designing streetscapes in high-rise environments based on people's visual experiences.

Previous studies discussed the use of eye-tracking as a research tool and its suitability in the field of urban design and architecture. They also integrated various tools from other research fields, both in laboratory-based investigations and outdoor experiments, that provide alternative design research methods and open up opportunities to make valuable contributions in architecture and urban design. However, to our knowledge, morphological 
studies using eye-tracking are relatively new. As an experimental method, in the current study, eye-tracking provides a more significant opportunity to analyze, quantify, and visualize the individual's visual interactions with the street interface configurations.

\section{Materials and Methods}

This section introduces the methodology used for the analyses of both the morphological features and pedestrians' visual perception (Figure 1). Regarding the street interface's configurations, interpretation was performed on a neighborhood scale; in fact, studying the overlapping of urban morphological elements in their relationship with public life required a scale that considered human proportions. As mentioned in Moudon's framework [35], the smallest "cell" of the city is the individual parcel of land, with its street(s) and building(s) [35]. Therefore, the micro-morphological analysis of the street interface can contribute to the main inquiries.

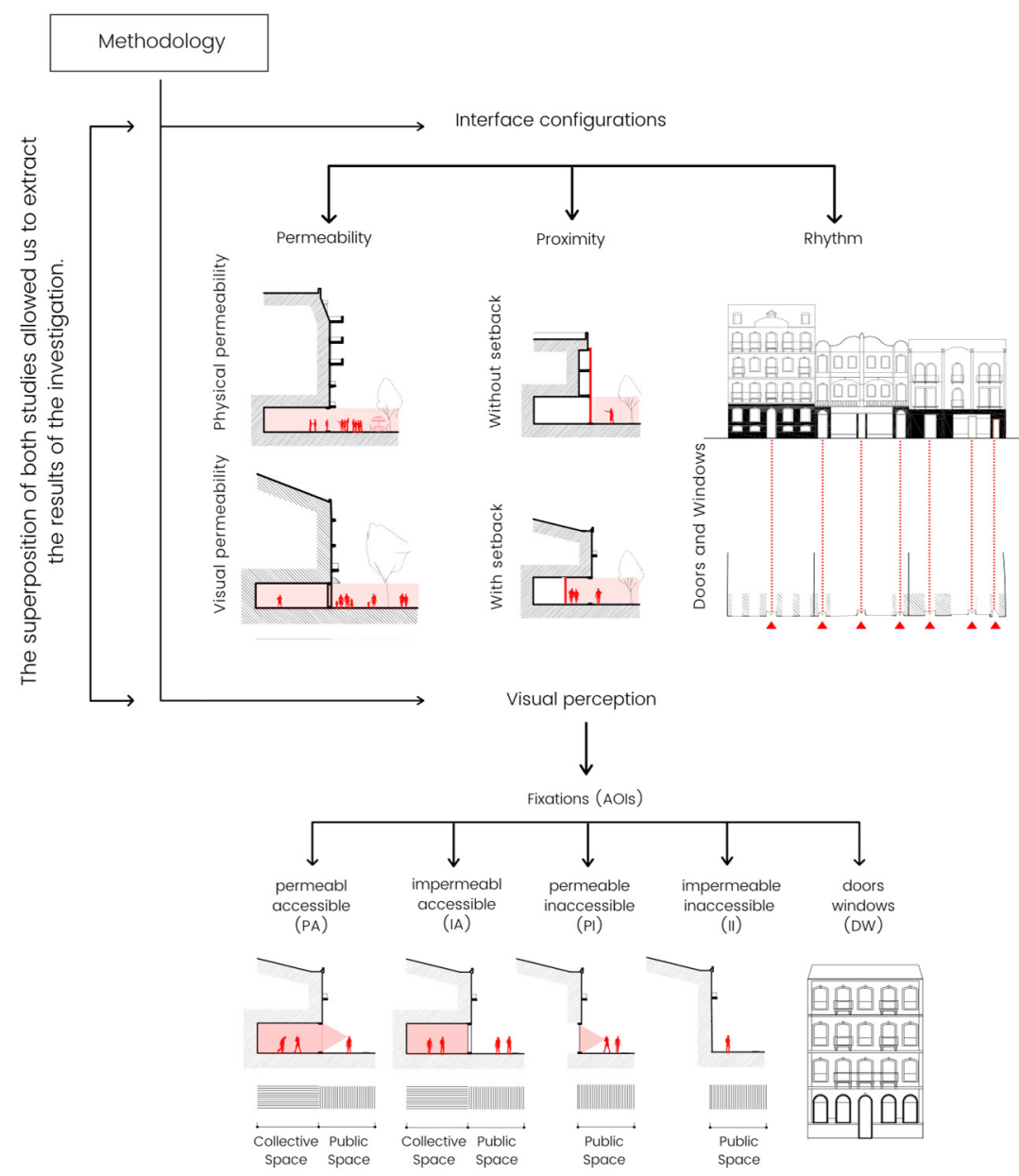

Figure 1. The research methodology: Interface configuration + Visual perception.

\subsection{The Case Study: Avenida da República, Lisbon}

Avenida da República is part of the central axis, which was a late 19th/early 20th century expansion plan for Lisbon (Portugal) conceived by Frederico Ressano Garcia. The street is a part of the Marquês de Pombal-Entrecampos axis, with a total length of approximately $2.5 \mathrm{~km}$. Avenida da República, characterized by a $1.5 \mathrm{~km}$ length and $60 \mathrm{~m}$ width, is part of Lisbon's main axis, located in the Avenidas Novas (Figure 2). Several landmarks are located within the avenue's morphological region, such as the bullfight arena in Campo Pequeno, and the new Parish Church of Nossa Senhora de Fátima (Figure S1) [64]. 


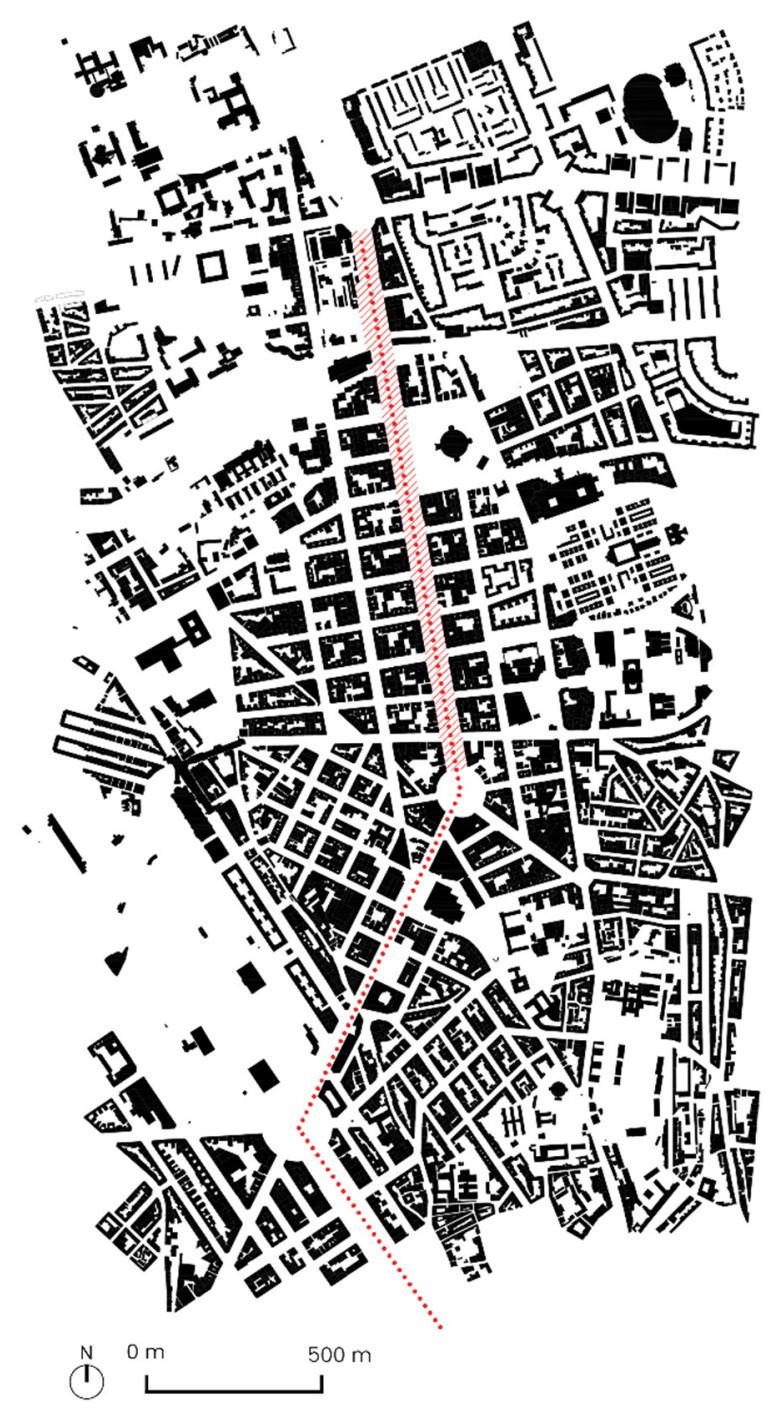

Figure 2. Avenida da República and the central axis of Lisbon within the built environment, Portugal.

From the mid-20th century until recently, the increased use of automobiles has transformed the avenue into a car-oriented street with more than ten traffic lanes in some parts of the street. In addition to the lack of safe and proper pedestrian spaces, the sidewalks have variable widths, physical barriers, and a lack of adequate pedestrian facilities, which has resulted in fatal consequences [65].

However, the street is currently undergoing socio-spatial transformations, which mainly coincide with the new urban regeneration strategy of 2014, giving rise to the new configuration of the urban profile that has attracted this research interest. The municipality strategy "Uma Praça em Cada Bairro" (literally "a square in every neighborhood") aimed to promote the quality of public spaces, including streets. The municipality plan promoted soft mobility modes, such as walking and cycling, and increased accessibility to public transportation. The main concept that has guided the transformation of the axis was the change in the street's morphology to return the street to the pedestrians as the primary users, increase the dimensions of the sidewalks, and revive the initial concept of the street as a boulevard with new tree alignments. Additionally, the transformation aimed to reduce the speed limit of private automobiles, minimize car parking, and balance the use of the space with the different modes of transport, including public transportation, which has created a robust urban image that promotes the continuity of the central axis. 


\subsection{Data Acquisition}

The study developed in this article was based on the analysis of three samples. Therefore, the criteria of the study samples were twofold: diversity and representativeness of street form. We conducted several drive-by and walk-by observations of the street to select the study samples and gain deep and exhaustive knowledge.

The selection considered the variety of interface configurations, whereby all the samples accommodate a range of different interface types, street partitions, types of business, street furniture, and the range of activities possible in each selected segment. In this regard, three samples were selected to represent three different street segments and build a typology of the street interfaces. The first sample, " $\mathrm{A}$ ", is located next to the Saldanha square. Sample " $\mathrm{B}$ " is in the middle of the street, while "C" is located near Entrecampos. Each section has been divided into two parts, the east and west sides of the street (Figure 3).

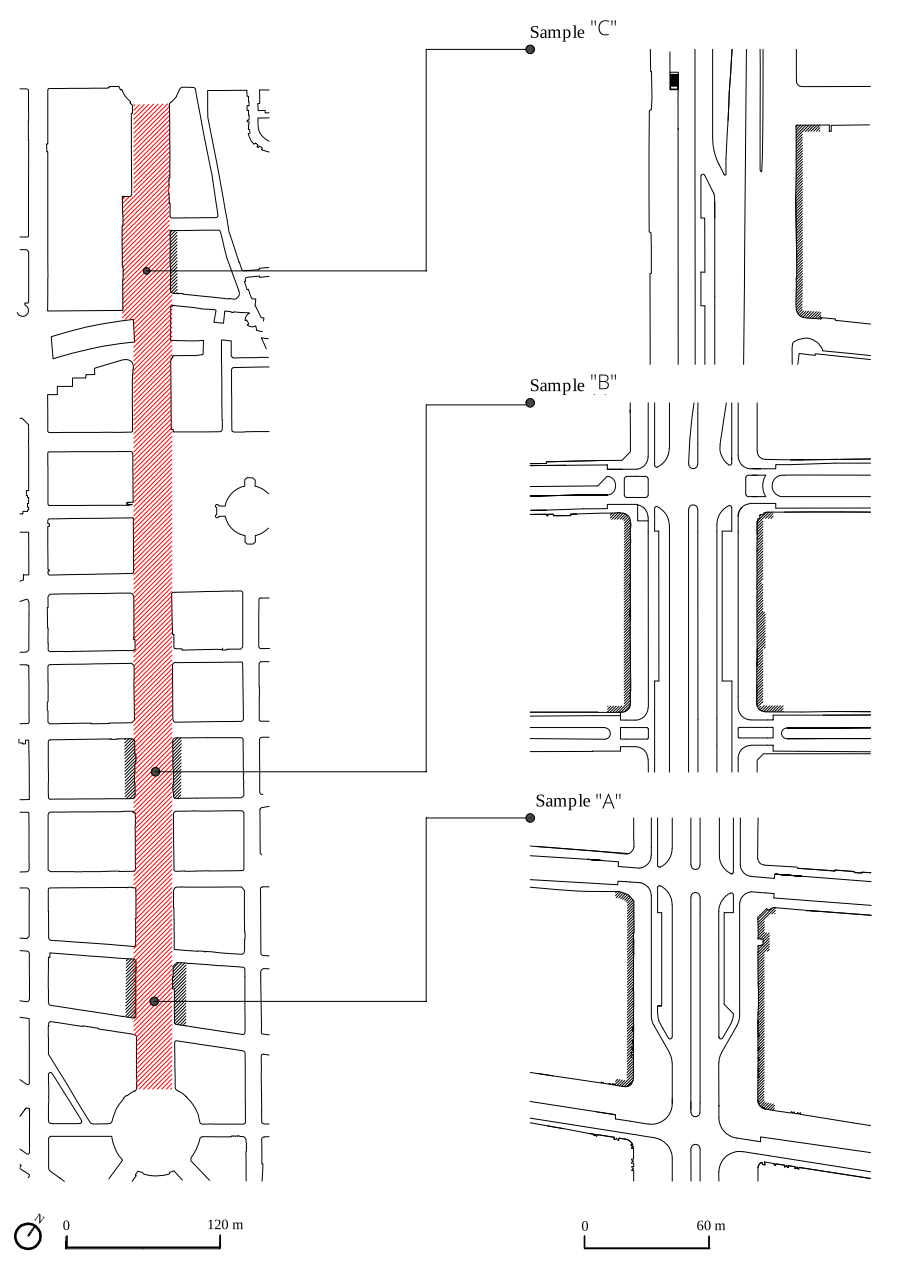

Figure 3. The selected samples for the analysis of Avenida da República, Lisbon.

The current investigation determined each selected sample's configurational properties and the pedestrians' potential visual perception of it at the ground floor level. As a first and fundamental step, the street interface configurations were analyzed for the most common variables: permeability (visual/physical), proximity (distance/adjacent), and rhythm (doors/windows), while pedestrians' visual preferences were analyzed using mobile eye-tracking glasses. The superposition of both studies allowed us to extract the results of the investigation. 


\subsubsection{The Variables of the Interface's Configuration}

The configuration study was applied to interpret the level of permeability (visual/ physical), proximity (distance/adjacent), and rhythm (doors/windows) of the street interface on the ground floor level. As these are morphological characteristics, they contribute to decoding the qualities of urban space that contribute to the richness of public life and social interaction (essential factors for street vitality). The interface configuration variables were as follows:

1. The street interface's permeability refers to the capacity for connection between one domain and another. As a property for the interface, visual permeability allows visual interactions between the two spaces delimited. Visual permeability is a crucial feature that encourages active interfaces and improves the urban experience, whereby it ensures interconnection with the surrounding realm. As stated by Jacobs (1995), "they invite you in, they show you what is there and, if there is something to sell or buy, they entice you" [14]. The measure of visibility was defined by studying how visually permeable the interface is. In this regard, the interface was considered as either visually permeable or impermeable. An interface can be visually permeable when the visuality degree of the interface is $50 \%$ or more. Additionally, the measure of visibility considered the use of space that is visible to the pedestrian. Therefore, defining the ground floors' uses was necessary, encouraging or conversely discouraging interaction between the street and the building;

2. Physical permeability refers to the street interface's property that allows pedestrians to physically enter the building's ground floor from the street. Specifically, it refers to public entrances that connect two realms. The access between the two spaces creates potential social activity and ensures pedestrians circulate in and nearby the interface. This variable has been defined only as the interfaces that allow pedestrians to cross from public space to private space without restrictions. The analysis of this variable was based on mapping each interface's collective spaces in the selected samples;

3. The proximity of the interface refers to the distance between the interface and the street (setback). The study of this variable was based on measuring how the building is adjacent to the street, that is, whether the interface is direct (without setback) or involves a space (with setback);

4. The rhythm variable measures the number of doors and windows located at different street interfaces that pedestrians perceive. The rhythm variable measures any entrance or passage that communicates between the public space and the private one, intended primarily for pedestrians. This variable aimed to quantify the "rhythm" of doors and windows (number of accesses per $100 \mathrm{~m}$ ) in the different configurations of interfaces pedestrians may encounter along their journey across the street.

\subsubsection{Eye-Tracking Experiment}

\section{- Participants}

Ten volunteers participated in the experiment (five male and five female), with an average age of 30 years (min. 23, max. 38, SD 4.52). The participants' vision was normal or corrected to normal. During the experiment, the participants were aware of the eye-tracking system's use and function, to help them act naturally. However, they were not informed of the study's intentions in order to avoid bias related to interface design. For the purposes of the research, none of the participants had an architectural or urban design background. Additionally, none of the participants lived or worked in the experiment location.

- Apparatus

The eye-tracking system used for this study was Pupil Invisible glasses, a headmounted eye tracker created by Pupil Labs. Pupil Invisible is a wearable glasses set up resembling a normal pair of glasses, which reduces social distortion and allows for working in all environments. The used mobile eye-tracking system provides robust gaze estimation in any environment, including streets, which is essential for this study. The tracker contains 
two inner cameras mounted onto the frame to record the eyes' movements, one on each side, and one exterior camera attached by a magnetic connector to the left temple, with a $90^{\circ} \times 90^{\circ}$ field of view to record the environment. The right temple contains a USB-C connector that connects the Pupil Invisible glasses to a smartphone running the tracker app. The output of the eye-tracking system used for this study was recorded videos that showed the participants' gaze position and coordinates as related to the outside image.

- Design and procedure

Five areas of interest (AOIs) were defined based on the variables of the interface configurations. These AOIs were permeable/accessible (PA); impermeable/accessible (IA); permeable/inaccessible (PI); impermeable/inaccessible (II); and doors/windows (DW). As the main aim of this experiment was to identify the type of interfaces that attract pedestrians, the current study examined the fixation points as the metric to analyze participants' visual perception of different AOIs. Fixations define the periods of time for which the eyes are relatively still, which determines the points on which pedestrians' eyes are focused [51]. Irwin (1992) indicated that the minimum duration for fixation is at least 150 ms. Thus, the minimum duration for a single fixation in this experiment was $150 \mathrm{~ms}$ [66]. Fixations in this study were measured by analyzing which points they occurred at and their duration. The analysis of each participant's visual perception was based on the ratio of fixation number and time spent on each AOI.

The eye-tracker was connected via a cable to a smartphone as the companion device handling all computation and storage of the recorded data in the Pupil Cloud. The calibration was undertaken using the Pupil Invisible Companion app for each participant in order to perform gaze estimation. This procedure involved asking participants to fixate on a series of specific points from various angles and distances to measure and calibrate their gaze accuracy. Multiple calibrations were undertaken to yield precise calibration.

After the calibration, each participant was introduced to their task. These tasks were divided among participants based on the type of activity related to walking (necessary and optional) in order to reveal causal relationships and test the hypotheses. The participants were divided into two groups, five participants each. One had the necessary task, and the other had the optional task, in order to increase realism in the experiment. These tasks have been categorized [17] and tested in several urban studies, and in previous eye-tracking experiments in outdoor environments [33]. The optional activities were strolling around the street or walking for a break; the necessary activity was walking to a destination.

Participants were asked to wear the eye-tracker and walk on each side of the street at each selected sample location, whereby each participant walked on each side of the three samples for a total of six routes. After each experiment, the participants were asked to express their feelings and opinions about the place in a few short statements. The duration of data collection required a maximum of two experiments a day. Therefore, the study was carried out on different days of the week, during the daytime, in fair weather conditions, between 7 April 2021 to 13 April 2021.

- Data Processing

After recording the participants' experiences using the Pupil Invisible Companion app, each participant's eye-tracking raw videos were uploaded separately and securely to the Pupil Cloud. Pupil Player v3.1.16, an open-source analysis software, was used for playback, video visualization, fixation coding, and analysis of fixation duration, location, and gaze path. Due to the challenging environment from the point of view of automated analysis, it was necessary to count, code, and go through each fixation manually in order to ensure valid data. For the purpose of the study, fixations were measured only when the eye was focused on the selected AOIs of the street interfaces, with a minimum duration of $150 \mathrm{~ms}$. This process was undertaken for each recorded video from each participant. All fixations' data were coded based on AOIs and exported to be compared, and then ultimately represented in the form of charts. 
The eye-tracking results were then juxtaposed with drawings of the street interfaces' morphological characteristics to provide a morphological interpretation of the relationship between street interfaces and visual perception that influences street livability. For each sample, the drawings were made according to the same graphic criteria and scales, using the classical architectural representation of spatial elements, including plans, cross-sections and façades, which can be compared and juxtaposed via visual perception analysis. The importance of studying the street interfaces related to the street segment and the context of the street itself explains the choice of multiple levels of resolution. These resolutions make it possible to study the street interfaces in relation to the street context.

\section{Results}

Studying public life has often been carried out through two main methods: interviews and personal observations. These methods have been proven as an effective means of understanding public life's pattern, activities, and data, regarding the numbers, ages, and genders of people in a public space [67]. However, applying these methods to the individual's experiential perception would restrict the opportunity to systematically analyze their visual perception of the built environment [45]. In light of this, the current study adds insight and evidence in line with previous eye-tracking experiments $[33,63]$ from the pedestrians' perspective, as the street's main users, showing how different configurations influence pedestrians' visual attention in order to understand their visual preferences. The current study permits us to experiment in a highly accurate way, with the quantification of livable public spaces, which implies Jane Jacobs's "bottom-up" approach to the involvement and participation of users as the center when designing vital cities.

The case study, Avenida da República, is a significant transit node with numerous bus stops and subway entrances. In terms of population, 13,484 individuals live in the area, corresponding to a density of 99.1 inhabitants/ha, which can be considered relatively low compared to other city areas. The average family size is 2.09 individuals. The buildings along the street are constructed in different architectural styles; some were built from the end of the 19th century to the middle of the 20th century with two to six floors. However, the majority of buildings (39.60\%) are between 10 and 12 floors in height.

Avenida da República is a lively street in a strategic location surrounded by commercial and tertiary activities, where three commercial centers meet: the Atrium Saldanha, the Monumental, and Campo Pequeno. The street, at eye level, facilitates mixed uses and a variety of activities, creating stimulating places for people. The study has shown that the three most common uses that occupy the ground floor along the street are services such as banks and telecom stores, among others (18.32\%); residential buildings and hotels (15.27\%), and restaurants and cafes (14.50\%) (Figure S2).

In the century-old construction of this artery, there are different forms of interfaces that depend on the functions at the ground floor level, but also on the time of construction. The street interface of Avenida da República is composed of a diverse and dynamic part of the street's public realm that allows interaction and connection between the morphological components: the street and the buildings. In a $1.5 \mathrm{~km}$ stretch, the street interfaces on the ground floor offer various shared spaces with different uses, structured as various continuous spaces, whether public or private, contributing to the street's vitality (Figure 4). 

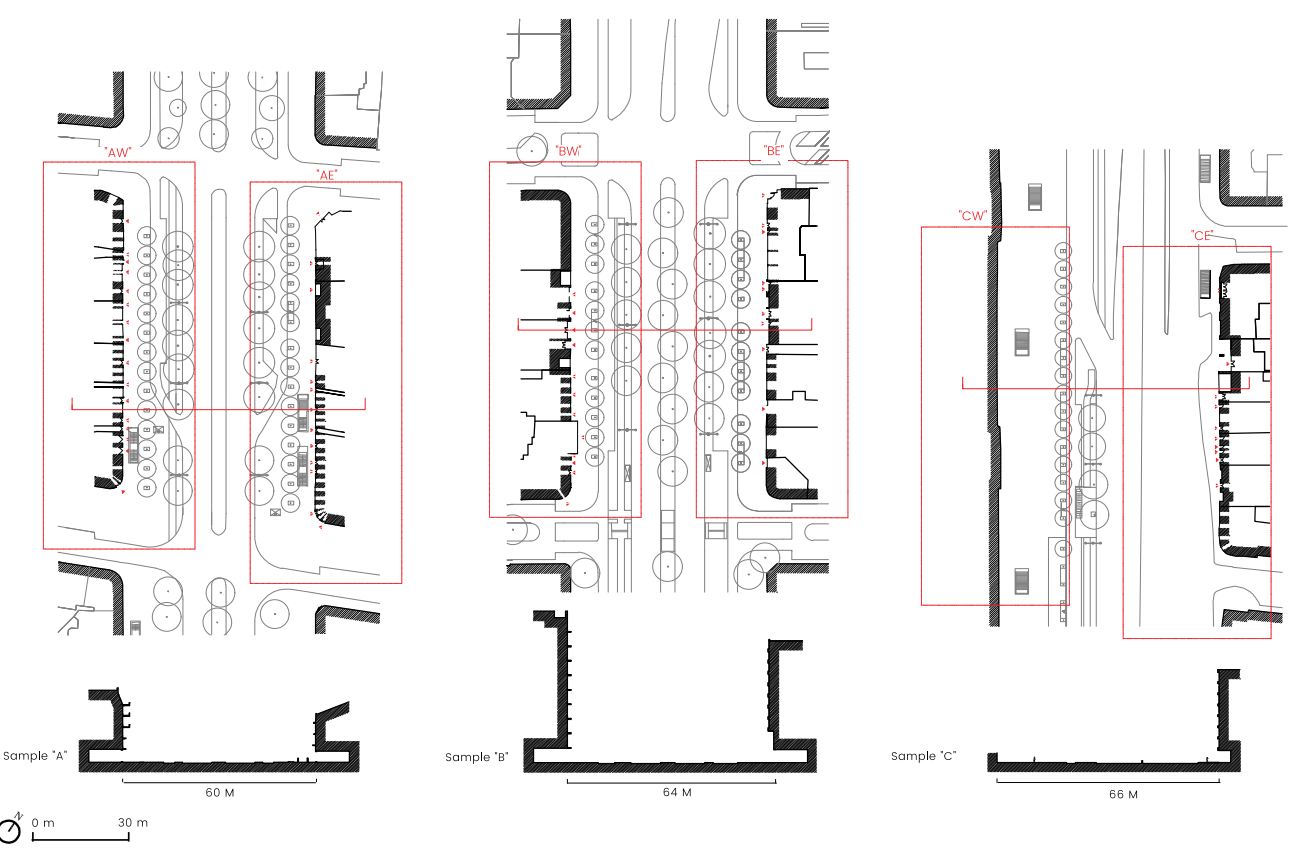

Figure 4. Plans and cross-sections of the three selected samples " $\mathrm{A}$ ", " $\mathrm{B}$ " and " $\mathrm{C}$ ".

The morphological study and experiment of pedestrians' visual preferences revealed two general categories in the case study. First, the study of samples " $\mathrm{A}$ " and " $\mathrm{B}$ " manifested five types of street interfaces: permeable/accessible (PA), impermeable/accessible (IA), permeable/inaccessible (PI), impermeable/inaccessible (II), and doors/windows (DW), with different percentages of occupation. These samples offered a variety of proximities, whereby some interfaces were adjacent to the sidewalk (without setback) and others had a setback. They also showed different ground floor uses that varied from restaurants to soft goods, quick services, and specialty, governmental, and residential services. However, sample " $A$ " is characterized by a wider sidewalk, from 17 to $9 \mathrm{~m}$, than sample " $\mathrm{B}$ ", at $9 \mathrm{~m}$, which supports, facilitates, and distributes pedestrian flows.

The study of sample " $A$ " manifested the five types of street interfaces. Sample "AE" was $98.1 \mathrm{~m}$ wide and had an interface height between 4.5 and $5 \mathrm{~m}$. The majority of the interfaces are permeable/accessible (PA), with a percentage of $49.69 \%$, compared to impermeable/inaccessible (II) interfaces, at $24.35 \%$. The results demonstrate that the ground floor on this side of sample " $\mathrm{A}$ " offered diverse uses, including restaurants, office building entrances, and furniture stores. They all provide access to the street, which, in turn, presents a continuity that creates a consistent rhythm in terms of doors and windows. Exceptions to this only arose in the impermeable/inaccessible (II) interfaces. On the other hand, sample "AW" was $92.54 \mathrm{~m}$ wide and between 4.5 and $5 \mathrm{~m}$ in interface height. The impermeable/inaccessible (II) interfaces were the most established interfaces, with a percentage of $36.29 \%$. Regardless, it offered more variety of uses on the ground floor than sample "AE", including restaurants, a fashion store, residential front entrances, a beauty salon, and office entrances.

Regarding sample " $\mathrm{B}$ ", the study showed that the sample accommodates all the selected variables of street interface configurations. The architecture of the buildings in sample "B" provides various characteristics that add richness to the streetscape, such as the painted ceramic tiles and carved traditional windows and columns. The interfaces of sample "BE" were $96.3 \mathrm{~m}$ wide and between 4 to $4.5 \mathrm{~m}$ in interface height $(33.38 \%)$, with a majority of impermeable/inaccessible (II) interfaces. This is reflected in the use of the ground floor, most of which was residential. However, the rhythm of doors and windows was found to ass a vibrant visual texture to the street interfaces. On the other side of the avenue, the study established that sample "BW" had a more significant number of possible uses, whereby a single building may accommodate multiple uses at eye level. 
The sample's interface was $95.75 \mathrm{~m}$ wide and between 4 and $5 \mathrm{~m}$ in height, most of which was impermeable/inaccessible (II) interface, with a percentage of $34.54 \%$.

The eye-tracking results of Samples " $\mathrm{A}$ " and " $\mathrm{B}$ " show that the permeable/accessible (PA) interfaces induced the greatest eye fixation for most participants (Figures 5 and 6). Regarding the study of visual perception in sample " $\mathrm{A}$ ", the results show that participants were visually attracted to permeable/accessible (PA) interfaces on average $28.95 \%$ of the time, in comparison to impermeable/accessible (25.57\%), doors/windows $(19.90 \%)$, impermeable/inaccessible (16.5\%), and permeable/inaccessible $(9.0897 \%)$. In sample " $\mathrm{B}$ ", we also found that participants spent more time looking at the permeable/accessible (PA) interfaces, with an average of $29.77 \%$ of the time, and doors/windows occupied $29.72 \%$.
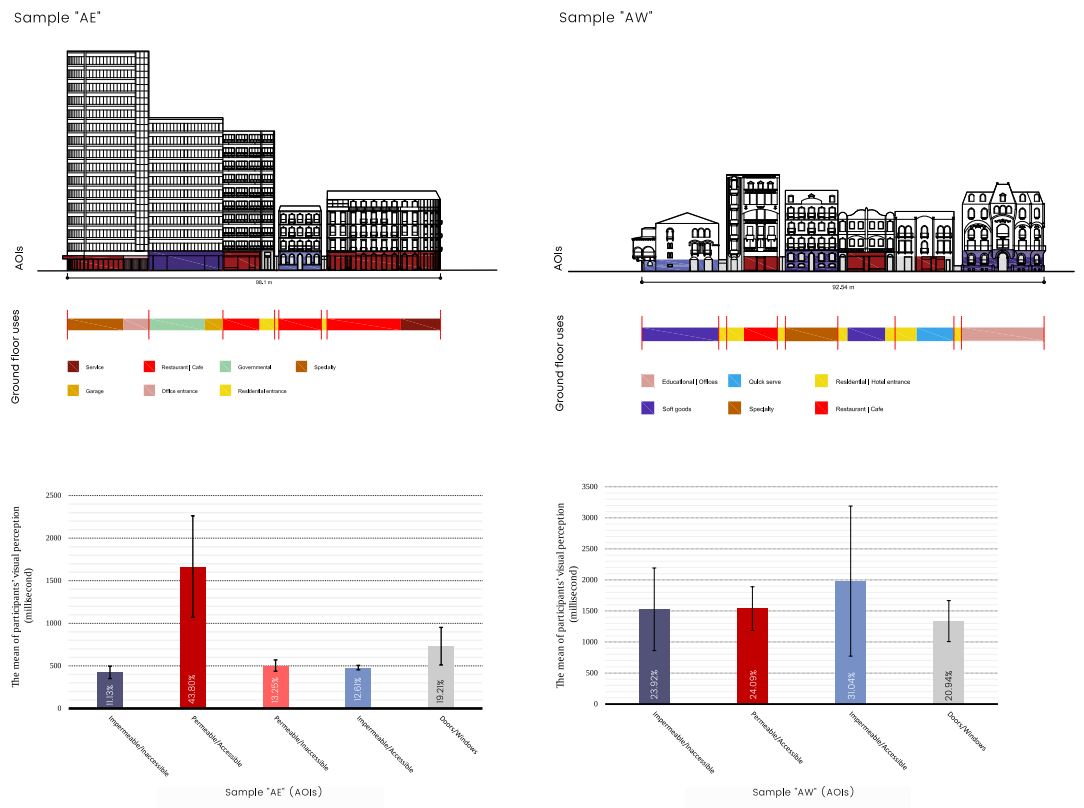

Figure 5. The percentage of participants' visual preference for street areas of interest (AOIs) in samples "AE" and "AW".

sample "BE"
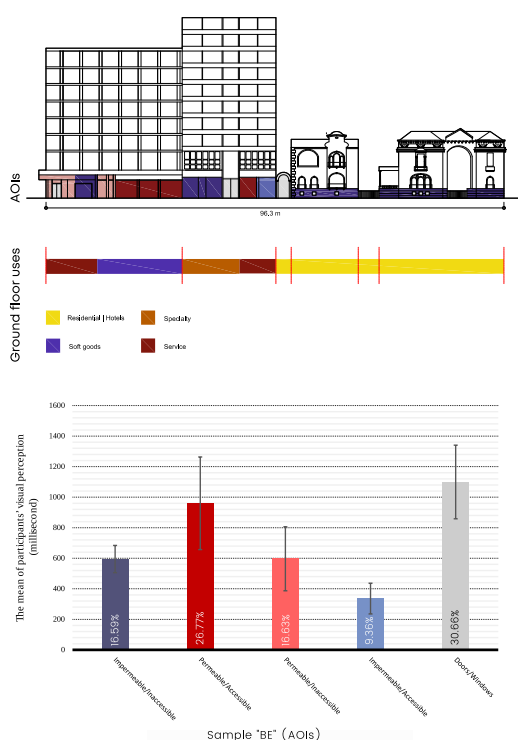

sample "BW"
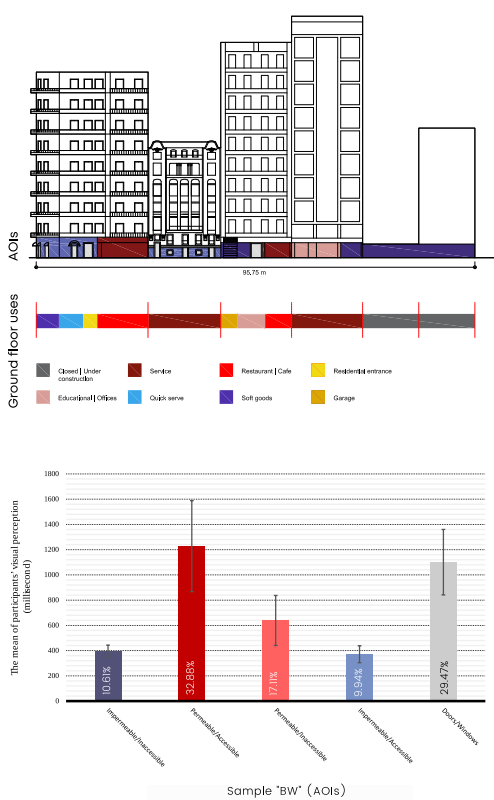

Figure 6. The percentage of participants' visual preference for street areas of interest (AOIs) in samples "BE" and "BW". 
The second category of the results refers to " $\mathrm{C}$ ", which presented a different form among the selected samples regarding street morphology, street interface configurations, and visual preferences. The street interfaces of sample " $\mathrm{C}$ " were divided into "CE", $93.25 \mathrm{~m}$ long, and "CW", $151.06 \mathrm{~m}$ long. Regarding sample "CE", the study showed that it was mainly impermeable/inaccessible (II) interfaces, which dominated the interface with a percentage of $74.07 \%$, while doors/windows (DW) occupied $21.01 \%$ and only $4.92 \%$ was occupied by permeable/accessible (PA) interfaces. The sample lacked diversity of street interface typologies and uses, such as was established in the first category. In sample "CE", the street interface would not allow communication between the street and the buildings, even with the continuous rhythm of doors and windows. The absence of interactive interfaces creates an unlivable street with a lack of social activities, that is, a street that is only for movement. At the same time, sample "CW" is margined by a vacant plot, offering a permeable/inaccessible (PI) interface without setback and a good rhythm of doors and windows compared to the other samples (Figure 7). Nevertheless, the eye-tracking results show that participants were attracted to the impermeable/inaccessible (II) interfaces on average $41.73 \%$ of the time, doors/windows $33.98 \%$, and permeable/accessible (PA) interfaces on average $24.29 \%$ of the time (Figure 8 ).

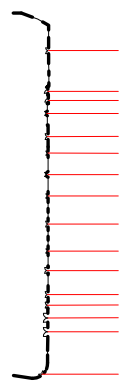

Sample "A"

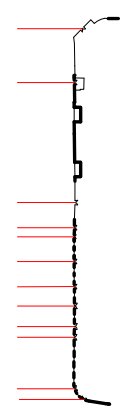

$0^{\prime \prime 2}$

$60 \mathrm{~m}$

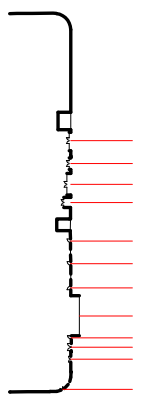

Sample "B"

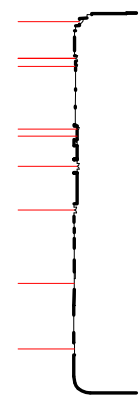

Figure 7. Plans of the three selected samples " $\mathrm{A}$ ", " $\mathrm{B}$ " and " $\mathrm{C}$ ", showing the rhythm and proximity of the street interfaces.
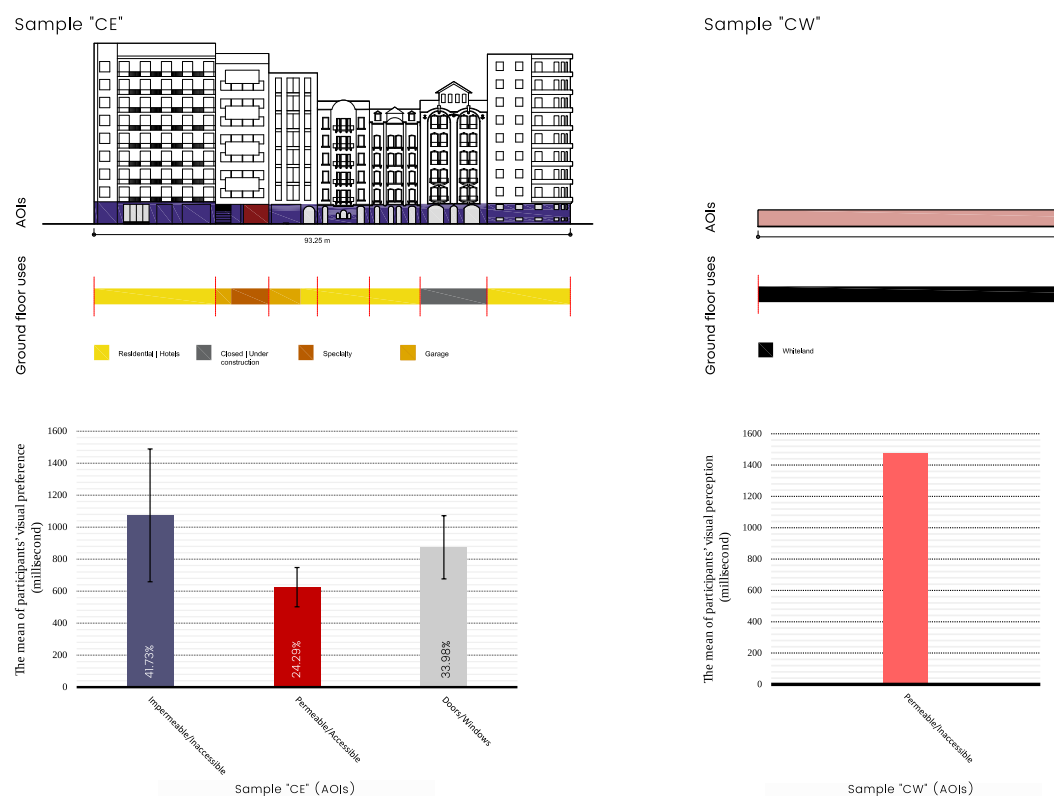

Figure 8. The percentage of participants' visual preference for street areas of interest (AOIs) in samples "CE" and "CW". 
The eye-tracking results show that permeable/accessible (PA) interfaces were the most visually attractive out of the three samples (Figure 9). On average, participants were visually attracted to these $25.49 \%$ of the time, in comparison to the doors/windows $(21.60 \%)$, permeable/inaccessible interfaces $(19.15 \%)$, impermeable/accessible interfaces $(17.73 \%)$, and impermeable/inaccessible interfaces (16.03\%). The study highlights that participants were more visually attracted to the interfaces of sample " $\mathrm{A}$ ", occupying $43.63 \%$ of their time, compared to sample " $\mathrm{B}$ " (34.11\%) and sample "C" $(22.26 \%)$.

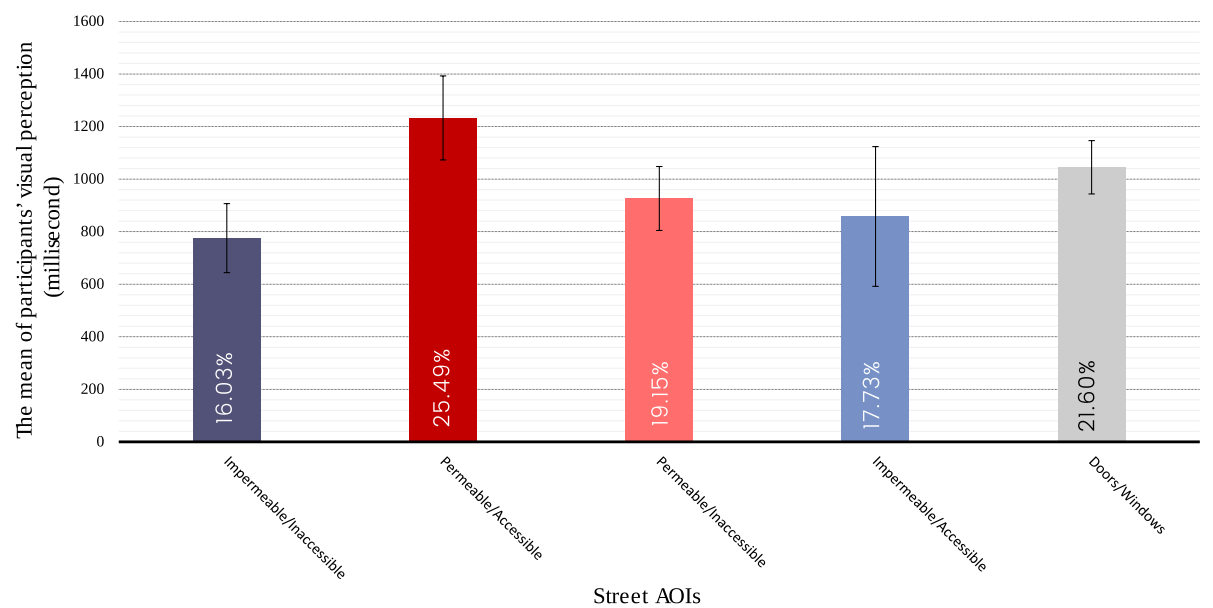

Figure 9. The percentage of participants' visual preference for street areas of interest (AOIs).

\section{Discussion}

The current study shows that the quantitative measurement of visual perception using mobile eye-tracking glasses contributes to studying the form of the street interface. In this study, an interdisciplinary methodology has been applied and tested in an arterial street, but this can also be used in broader investigations. The current study addresses the limitations of the study of a street interface as a physical entity related to visual perception, involving pedestrians as a center of creating visually engaging streets that contribute to composing a spatial framework for liveability. We consider that the study contributes to connecting street livability on a micro-morphological scale to the way people visually perceive a street, by addressing the main question: What are the most important variables of street interface configurations that influence pedestrians' visual perception?

As hypothesized, the findings demonstrate that pedestrians interacted visually with the permeable/accessible (PA) interfaces more than other configurations of street interfaces. This can be observed in samples " $A$ " and " $B$ ", which showed that pedestrians spent more time visually interacting with the permeable and accessible interfaces than any other AOIs. These interfaces present a dialogue that transfers activities from the private to the public, from the buildings to the street. The participants' high visual preference for this type of interface is due to the street interface's configurations, ground-floor uses, and the sidewalk's widths and partitions (Figure 10).

Regarding the street interface configurations, this study established that different interface typologies produce various frameworks for public life, and induced the participants to spend different amounts of time looking at them. These variables attracted participants' visual attention as pedestrians are visually attracted to interfaces that offer a connection between public and private spaces. Permeability and accessibility comprise the relationship between a street and buildings, giving a new extension to the space of the sidewalk for different public uses, such as outdoor seating (Figure S3). Thus, the street interface acquires value when it becomes part of public life, allowing interaction between the buildings and the street. It can be said that these variables are socio-spatial entities useful for multiple activities through which people live their everyday life. 

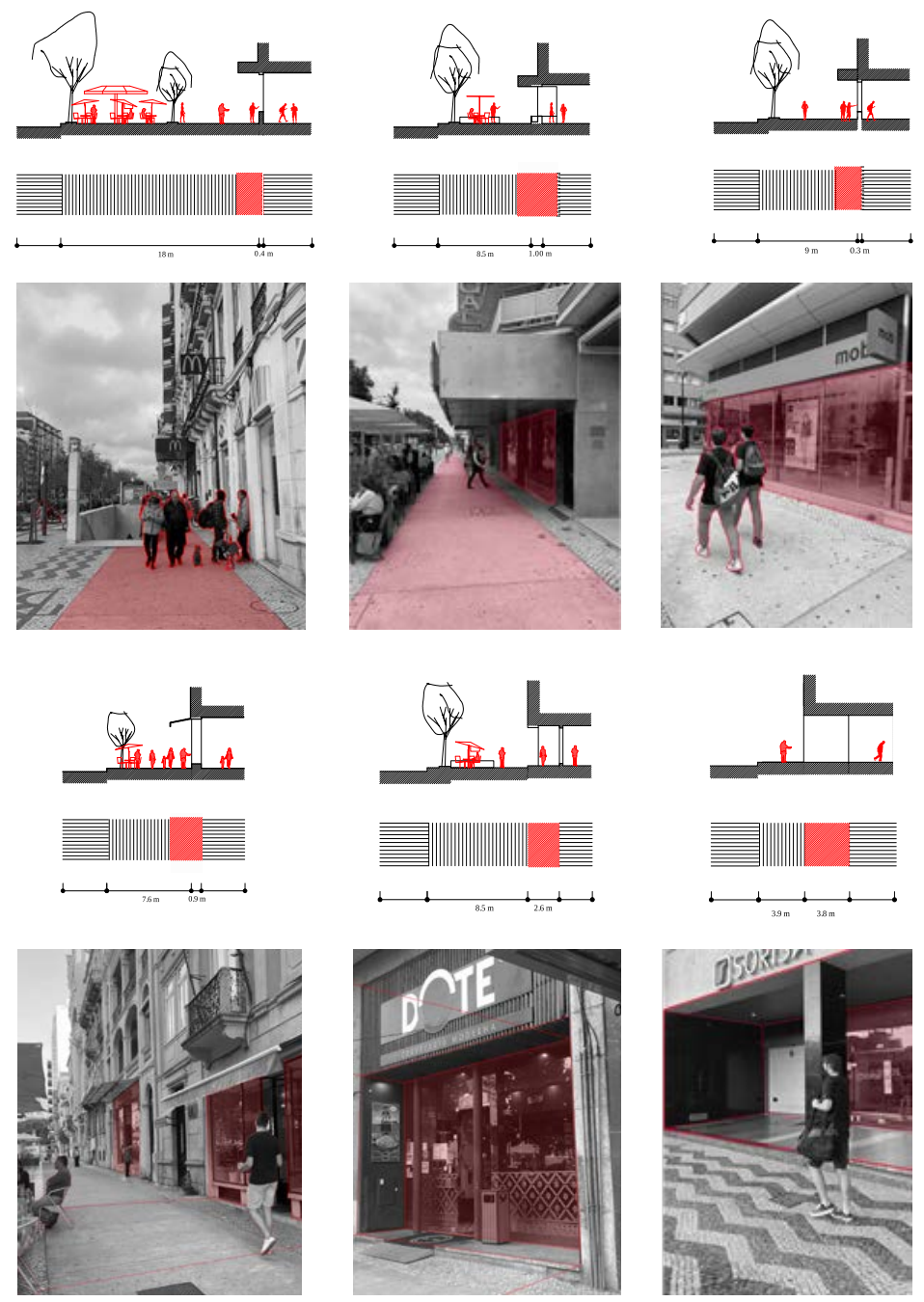

Figure 10. Different types of permeable and accessible interfaces that attract the participants' visual attention.

This is an important finding in understanding the way in which the interface between the public and private plays a critical role in public life by allowing interaction and communication with the surroundings. This can be observed by comparing the amount of time participants spent visually with samples " $\mathrm{A}$ " and " $\mathrm{C}$ ". As such, permeable and accessible interfaces are not only the most visually stimulating configuration, but also produced shared spaces accommodating various activities. This suggests that permeable and accessible interfaces can be considered physical entities that enhance the dialogue in the transition space and promote urbanity, which enriches social life in different ways. They are a vital element of the street, and one of the main dimensions of street livability.

The importance of street interfaces' configurations and forms for users has been discussed in the fields of psychology and neuroscience. Based on psychological principles, William James [68] stated that "stimulation is the indispensable requisite for pleasure in an experience" (p. 626). This perspective outlines the fundamental role of stimulation in enhancing an individual's experience. In this regard, street interface configurations can be prime stimulators of human behavior that may either enrich pedestrians' experience or create an experience of boredom. Colin Ellard (2015) [69] conducted an experimental study in environmental psychology and neuroscience to assess pedestrians' emotional states in relation to different street façades. The study showed that the designs of façades influence the psychological states of pedestrians, whereby blank façades create a sense of tedium compared to active façades. It has been demonstrated that the general design of the street interface influences the psychological and emotional state of pedestrians. 
Participants' visual preferences were also found to be related to the ground floor uses. The study shows that permeable and accessible interfaces, as in sample "AE", "AW" and "BW", constitute the commercial and social core. Restaurants and social activities were observed, linking permeability and accessibility, which attracted participants' eyes immediately. Permeable and accessible interfaces promoted the connection between the ground floor and the street, whereby stores opened their doors to the public and demarcated the territory facing the street through elements such as advertisements, tables, and seats, which offered different sensory information and social stimuli, including the visual (Figure S4).

Further, the comparisons reveal that the width and partitions of the sidewalk correlated with the participants' visual preference. As demonstrated, samples " $A$ " and " $B$ " presented various interface configurations and ground floor uses; however, the amount of time that participants visually spent with sample " $\mathrm{A}$ " was more than that with sample " $\mathrm{B}$ " (Figure S5). This suggests that the width of the sidewalk in sample " $\mathrm{A}$ " offered an extension of the ground floor, which created points of contact between the two realms, characterized by architectural elements such as pillars, entrance hallways, and shop windows that generated intense interaction. The sidewalk width provided a space that buffered pedestrians from opening doors and structural elements, and created more space for sidewalk cafés, store entrances, retail displays, and waiting. This feature was absent in sample " $\mathrm{C}$ ", where the sidewalk was narrow and adjacent to the roadway area, creating a sense of unsafety (Figure S6). Additionally, the sidewalk contained several physical barriers that obstructed participants' visual perception and movement, which manifested in the eye-tracking results as less visual attractiveness than in samples " $A$ " and " $B$ ".

Our results cast new light on the significance of doors and windows in pedestrian visual preferences. The findings of the experiment show that doors and windows welcomed participants' visual attention. The results show that pedestrians were visually attracted to doors and windows more than permeable and inaccessible interfaces. In line with previous studies, the current investigation provides evidence for the importance of the configurations of the street interface in shaping active street frontages [21,30,70-72].

We consider that our research emphasizes the importance of an interdisciplinary methodology composed of a morphological study and visual perception, overcoming the limitations of the measurement of livability in urban areas that the studies analyzed did not address. In light of this, the study develops a morphological interpretation of the street interfaces, particularly on the ground floor level, that promotes potential social interaction and visual engagement in the form of a more extensive investigation. Overall, within the framework of several street interface studies and studies of visual perception, our study provides new insight into the configurations of the street interface in relation to pedestrian visual preference using mobile eye-tracking glasses.

The current investigation was carried out via a pilot study of Avenida da República, Lisbon, as an exemplary arterial street that has undergone an enormous transformation during the last few years. The blending of a morphological study with visual interactions using mobile eye-tracking glasses in the outdoor environment is a relatively new approach. Nevertheless, we recognize that there are a number of limitations that require further consideration. There are also opportunities to generate testable hypotheses for future research.

The main limitations of the current investigation were, firstly, that the study did not measure how different material, complexity, and architectural elements of the street interface influence participants' visual preference. Moreover, the current study focused on the general typologies of the most common street interface configurations, ground floor uses, and sidewalk partitions and widths. Future research could further develop and examine architectural features and street interface materialities associated with street livability, including permeability, variety, legibility, robustness, visual appropriateness, richness, and personalization [26]. A second potential limitation is that the present study focused only on the type of street interfaces, excluding other elements associated with 
street livability, particularly people's actions and natural greenery, which may contribute to visual preference, as well as studying distracting elements such as cars, parking, and advertisements. Methodologically, some limitations include the use of a small number of participants, and the coding and counting of participants' gaze fixations manually. However, the future development of the eye-tracking system for variable and dynamic environments may open new opportunities for future investigations.

While recognizing the study's limitations, we believe the current investigation represents a starting point for future studies of street interface configurations and potential relations with pedestrian visual perception using mobile eye-tracking glasses. Therefore, the contribution of previous eye-tracking experiments was essential for the present research, as together this lays a new foundation for future investigations using mobile eye-tracking to study other areas of interest. In this context, for example, this method could be integrated with mobile electroencephalography (EEG) devices as a research methodology. The developments of commercial mobile electroencephalography (EEG) devices make it possible to monitor the brain and cognition in a real-world environment [73]. Integrating mobile EEG devices and mobile eye-tracking glasses would provide a robust understanding of pedestrians' spatial cognition and emotional states.

The current investigation offers empirical insight into the importance of street interface configurations in shaping public life, by engaging users in a real-life situation, as the bases for livable and active streets. This adds value to previous studies that discussed street interfaces' spatial, social, and cultural conditions $[21,27,31,33,74]$. As we understand cities' elements in terms of types [75], the current investigation shows how different typomorphological configurations of street interfaces influence pedestrians' visual perceptions. In this regard, typo-morphological investigation, as an approach to urban morphology, can not only elucidate patterns and types of morphological configurations with an intuitive understanding based on architectural or urban design, but can also reveal the visual perception of these configurations.

\section{Conclusions}

Arterial streets are the main space of the street network, as well as public spaces and other collective spaces, as they behave as the city's backbone. Due to their characteristics, arterial streets offer different opportunities for developments and regenerations of urban areas. Developing arterial streets can make them a powerful urban attraction element that generates livability, wherein they are characterized by various activities, including commerce, services, institutions, culture, and leisure. These characteristics have shed light on the need to understand street interface configurations that foster new ways of shaping better spaces and livable arterial streets.

The findings demonstrate that the permeable and accessible interfaces attracted participants' gaze more than any other street interfaces, due to the configurations, ground-floor use, and the sidewalks' widths and partitions. The current investigation emphasizes the importance of considering users' participation in the design process. Consequently, measuring and understanding users' responses to the environment according to their perceptions is essential to investigating its quality. Accordingly, using alternative methods that merge quantitative and qualitative measurements to assess the complexity of today's urban dynamics, flows, and activities can offer unprecedented and effective opportunities to enrich space-user interaction.

Supplementary Materials: The following are available online at https://www.mdpi.com/article/ 10.3390/su132011442/s1, Figure S1: The central axis of Lisbon and the surrounding landmarks, Figure S2: Atlas for decoding the urban form of Avenida da República, Lisbon, Figure S3: Plans and cross-sections of the three selected samples " $\mathrm{A}$ ", " $\mathrm{B}$ " and " $\mathrm{C}$ ", showing the visual and physical permeability of the street interfaces, Figure S4: The percentages of the ground-floor uses in Avenida da República and in the three samples "A", "B", and " $\mathrm{C}$ ", Figure S5: The percentage of participants' visual preference of the three samples " $A$ ", " $B$ ", and " $C$ ", Figure S6: The sidewalk width and partitions of samples " $\mathrm{A}$ ", " $\mathrm{B}$ ", and " $\mathrm{C}$ ". 
Author Contributions: Conceptualization, N.S.A.M., F.D.C. and S.B.P.; methodology, N.S.A.M. and S.B.P.; software, N.S.A.M.; validation, N.S.A.M., F.D.C. and S.B.P.; formal analysis, N.S.A.M. and S.B.P.; investigation, N.S.A.M., F.D.C. and S.B.P.; resources, N.S.A.M.; data curation, N.S.A.M.; writingoriginal draft preparation, N.S.A.M.; writing-review and editing, N.S.A.M., F.D.C. and S.B.P.; visualization, N.S.A.M.; supervision, S.B.P.; project administration, N.S.A.M.; funding acquisition, N.S.A.M. All authors have read and agreed to the published version of the manuscript.

Funding: This research was funded by the Saudi Arabian Cultural Mission in Spain: FG-323113 and CIAUD - Research Centre for Architecture Urbanism and Design, Lisbon School of Architecture, Universidade de Lisboa, 1349-063 Lisboa, Portugal.

Institutional Review Board Statement: Not applicable.

Informed Consent Statement: Not applicable.

Conflicts of Interest: The authors declare no conflict of interest.

\section{References}

1. Batty, M. The New Science of Cities; The MIT Press: Cambridge, MA, USA, 2013.

2. Carlson, C.; Semra, A.; Gardner, K.; Rogers, S. Complexity in Built Environment, Health, and Destination Walking: A Neighborhood-Scale Analysis. J. Urban Health 2012, 89, 270-284. [CrossRef]

3. Jacobs, J. The Death and Life of Great American Cities; Vintage Books: New York, NY, USA, 1961.

4. Jacobs, A.B.; Macdonald, E.; Yodan, R. The Boulevard Book History, Evolution, Design of Multiway Boulevards; MIT Press: Cambridge, MA, USA, 2002.

5. Marshall, W.; Garrick, N.; Marshall, S. Street Networks. Handbook on Transport and Development; Hickman, R., Givoni, M., Bonilla, D., Banister, D., Eds.; Edward Elgar Publishing: Cheltenham, UK, 2015.

6. Putnam, R.D. Bowling Alone: The Collapse and Revival of American Community; Simon \& Schuster: New York, NY, USA, 2001.

7. Appleyard, D.; Lintell, M. The Environmental Quality of City Streets: The Residents' Viewpoint. J. Am. Inst. Plan. 1972, 38, 84-101. [CrossRef]

8. Bosselmann, P.; Macdonald, E.; Kronemeyer, T. Livable Streets Revisited. J. Am. Plan. Assoc. 1999, 65, 168-180. [CrossRef]

9. Jacobs, A.; Appleyard, D. Toward an Urban Design Manifesto. J. Am. Plan. Assoc. 1987, 53, 112-120. [CrossRef]

10. Macdonald, E. Street-Facing Dwelling Units and Livability: The Impacts of Emerging Building Types in Vancouver's New High-Density Residential Neighbourhoods. J. Urban Design 2005, 10, 13-38. [CrossRef]

11. Lynch, K. The Image of the City; The MIT Press: Cambridge, MA, USA, 1960.

12. Marshall, S. A First Theoretical Approach to Classification of Arterial Streets. In ARTISTS Deliverable D1.1; University of Westminster: London, UK, 2002.

13. Ewing, R.; Handy, S. Measuring the Unmeasurable: Urban Design Qualities Related to Walkability. J. Urban Design 2009, 14, 65-84. [CrossRef]

14. Jacobs, A. Great Streets; The MIT Press: Cambridge, MA, USA, 1995.

15. Mehta, V. The Street: A Quintessential Social Public Space, 1st ed.; Routledge: New York, NY, USA, 2013.

16. Appleyard, D. Livable Streets; University of California Press: Berkeley, CA, USA, 1981.

17. Gehl, J. Cities for People; Island Press: London, UK, 2010.

18. Hall, E. The Hidden Dimension; The Bodley Head: London, UK, 1966.

19. Lofland, L. The Public Realm: Exploring the City's Quintessential Social Territory; Aldine de Gruyter: New York, NY, USA, 1998.

20. Gehl, J. Life between Buildings; Van Nostrand-Reinhold: New York, NY, USA, 1987.

21. Gehl, J.; Kaefer, L.J.; Reigstad, S. Close encounters with buildings. Urban. Ir Archit. 2005, 29, 70-80. [CrossRef]

22. Franck, K.A.; Quentin, S. Loose Space: Possibility and Diversity in Urban Life; Routledge: New York, NY, USA, 2006.

23. Glaser, M.; van 't Hoff, M.; Karssenberg, H.; Laven, J.; van Teeffelen, J. The City at Eye Level: Lessons for Street Plinths; Eburon: Delft, The Netherlands, 2012.

24. Alexander, C.; Ishikawa, S.; Silverstein, M. A Pattern Language; Oxford University Press: Oxford, UK, 1977.

25. Anderson, S. On Streets: Streets as Elements of Urban Structure; MIT Press: Cambridge, MA, USA, 1991.

26. Bently, I.; Alcock, A.; Murrain, P.; McGlynn, S.; Smith, G. Responsive Environments: A Manual for Designers; Architectural Press: London, UK, 1985.

27. Dovey, K.; Wood, S. Public/Private Urban Interfaces: Type, Adaptation, Assemblage. J. Urban. 2015, 8, 1-16. [CrossRef]

28. Hillier, B.; Hanson, J. The Social Logic of Space; Cambridge University Press: New York, NY, USA, 1984.

29. Sitte, C. City Planning According to Artistic Principles; Random House: New York, NY, USA, 1965.

30. Bobić, M. Between the Edges: Street-Building Transition as Urbanity Interface; Thoth Publishers: Bussum, The Netherlands, 2004.

31. Kamalipour, H. Mapping Urban Interfaces A Typology of Public/Private Interfaces in Informal Settlements. Spaces Flows Int. J. Urban Extra Urban Stud. 2016, 8, 1-12. [CrossRef] 
32. Milliken, P.; Hollander, J.B.; Sussman, A.; Minyu, S. Identifying Biophilic Design Elements in Streetscapes A Study of Visual Attention and Sense of Place. In Urban Experience and Design: Contemporary Perspectives on Improving the Public Realm; Hollander, J.B., Sussman, A., Eds.; Routledge: New York, NY, USA, 2021.

33. Simpson, J.; Thwaites, K.; Freeth, M. Understanding Visual Engagement with Urban Street Edges along Non-Pedestrianised and Pedestrianised Streets Using Mobile Eye-Tracking. Sustainability 2019, 11, 4251. [CrossRef]

34. Conzen, R.G.M. Alnwick, Northumberland. A Study in Town-Plan Analysis; George Philip And Son Ltd.: London, UK, 1960.

35. Moudon, A.V. Urban Morphology as an Emerging Interdisciplinary Field. Urban Morphol. 1997, 1, 3-10.

36. Rapoport, A. Human Aspects of Urban Form: Towards a Man-Environment Approach to Urban Form and Design; Pergamon Press: Oxford, UK, 1977.

37. Perovic, S.; Folic, N.K. Visual Perception of Public Open Spaces in Niksic. In Proceedings of the ASIA Pacific International Conference on Environment-Behavioral Studies, Mercure Le Sphinx Cairo Hotel, Giza, Egypt, 31 October-2 November 2012.

38. Cullen, G. Townscape; The architectural Press: London, UK, 1961.

39. Appleyard, D.; Lynch, K.; Myer, J.R. The View from the Road; The MIT Press: Cambridge, MA, USA, 1964.

40. Bacon, E.N. Design of Cities, Revised Edition; Penguin Book: London, UK, 1976.

41. Banerjee, T.; Loukaitou-Sideris, A. Companion to Urban Design; Routledge: New York, NY, USA, 2011.

42. Dzebic, V.; Perdue, J.; Ellard, C.G. The Influence of Visual Perception on Responses towards Real-World Environments and Application towards Design. Intell. Build. Int. 2013, 5, 29-47. [CrossRef]

43. Evans, G.W. The Built Environment and Mental Health. J. Urban Health Bull. N. Y. Acad. Med. 2003, 80, 536-555. [CrossRef] [PubMed]

44. Goss, J. The 'Magic of the Mall': An Analysis of Form, Function, and Meaning in the Contemporary Retail Built Environment. Ann. Assoc. Am. Geogr. 1993, 83, 18-47. [CrossRef]

45. Duchowski, A.T. Eye Tracking Methodology: Theory and Practice, 3rd ed.; Springer International Publishing: Cham, Switzerland, 2017.

46. Bergstrom, J.R.; Schall, A. Eye Tracking in User Experience Design; Morgan Kaufmann: Waltham, MA, USA, 2014.

47. Fotios, S.; Uttley, J.; Cheal, C.; Hara, N. Using Eye-Tracking to Identify Pedestrians' Critical Visual Tasks, Part 1. Dual Task Approach. Lighting Res. Technol. 2014, 47, 133-148. [CrossRef]

48. Holmqvist, K.; Nystrom, M.; Andersson, R.; Dewhurst, R.; Jarodzka, H.; Weijer, J. Eye Tracking A Comprehensive Guide to Methods, Paradigms, and Measures; Oxford University Press: Oxford, UK, 2011.

49. Zurawicki, L. Neuromarketing: Exploring the Brain of the Consumer; Springer: Boston, MA, USA, 2010.

50. Matin, E. Saccadic Suppression: A Review and an Analysis. Psychol. Bull. 1974, 81, 899-917. [CrossRef]

51. van Renswoude, D.; Raijmakers, M.; Koornneef, A.; Johnson, S.; Hunnius, S.; Visser, I. Gazepath: An Eye-Tracking Analysis Tool That Accounts for Individual Differences and Data Quality. Behav. Res. Methods 2018, 50, 834-852. [CrossRef]

52. Rahal, R.M.; Fiedler, S. Understanding Cognitive and Affective Mechanisms in Social Psychology through Eye-Tracking. J. Exp. Soc. Psychol. 2019, 85, 103842. [CrossRef]

53. Harezlak, K.; Kasprowski, P. Application of Eye Tracking in Medicine: A Survey, Research Issues and Challenges. Comput. Med Imaging Graph. 2017, 65, 176-190. [CrossRef] [PubMed]

54. Santos, R.; Oliveira, J.; Rocha, J.; Giraldi, J. Eye Tracking in Neuromarketing: A Research Agenda for Marketing Studies. Int. J. Psychol. Stud. 2015, 7, 32-42. [CrossRef]

55. Kaakinen, J.K. What Can Eye Movements Tell Us about Visual Perception Processes in Classroom Contexts? Commentary on a Special Issue. Educ. Psychol. Rev. 2020, 33, 169-179. [CrossRef]

56. Krstić, K.; Šoškić, A.; Ković, V.; Holmqvist, K. All Good Readers Are the Same, but Every Low-Skilled Reader Is Different: An Eye-Tracking Study Using PISA Data. Eur. J. Psychol. Educ. 2018, 33, 521-541. [CrossRef]

57. Ergan, S.; Radwan, A.; Zou, Z.; Tseng, H.; Han, X. Quantifying Human Experience in Architectural Spaces with Integrated Virtual Reality and Body Sensor Networks. J. Comput. Civ. Eng. 2018, 33, 04018062. [CrossRef]

58. Lisińska-Kuśnierz, M.; Krupa, M. Suitability of Eye Tracking in Assessing the Visual Perception of Architecture-A Case Study Concerning Selected Projects Located in Cologne. Buildings 2020, 10, 20. [CrossRef]

59. Zou, Z. Where Do We Look? An Eye-Tracking Study of Architectural Features in Building Design. In Proceedings of the 35th CIB W78 2018 Conference: IT in Design, Construction, and Management, Chicago, IL, USA, 1-3 October 2018.

60. Andreani, S.; Sayegh, A. Augmented Urban Experiences: Technologically Enhanced Design Research Methods for Revealing Hidden Qualities of the Built Environment. In Proceedings of the 37th Annual Conference of the Association for Computer Aided Design in Architecture, Cambridge, MA, USA, 2-4 November 2017; pp. 82-91.

61. Noland, R.B.; Weiner, M.D.W.; Gao, D.; Cook, M.P.; Nelessen, A. Eye-Tracking Technology, Visual Preference Surveys, and Urban Design: Preliminary Evidence of an Effective Methodology. J. Urban. 2017, 10, 98-110. [CrossRef]

62. Vainio, T.; Jokinen, A.; Karppi, I.; Leino, H. Towards Novel Urban Planning Methods-Using Eye-Tracking Systems to Understand Human Attention in Urban Environments. In Proceedings of the 2019 CHI Conference on Human Factors in Computing Systems, Glasgow, UK, 4-9 May 2019.

63. Spanjar, G.; Surenbroek, F. Eye-Tracking the City: Matching the Design of Streetscapes in High-Rise Environments with Users' Visual Experiences. J. Digit. Landsc. Archit. 2020, 5, 374-385. [CrossRef]

64. Silva, R.H. Das Avenidas Novas à Avenida Berna. Rev. De História Da Arte 2006, 2, 126-141. 
65. Câmara Municipal de Lisboa. Uma Praça Em Cada Bairro: Intervenções Em Espaço Público; Câmara Municipal de Lisboa: Lisboa, Portugal, 2015.

66. Irwin, D.E. Visual Memory Within and Across Fixations. In Eye Movements and Visual Cognition: Scene Perception and Reading; Rayner, K., Ed.; Springer: New York, NY, USA, 1992.

67. Gehl, J.; Svarre, B. How to Study Public Life; Island Press: Washington, DC, USA, 2013.

68. James, W. The Principles of Psychology; Henry Holt \& Company: New York, NY, USA, USA, 1890; Volume 1, p. 626.

69. Ellard, C. Places of the Heart: The Psychogeography of Everyday Life; Bellevue Literature Press: New York, NY, USA, 2015.

70. Heffernan, E.; Heffernan, T.; Pan, W. The Relationship between the Quality of Active Frontages and Public Perceptions of Public Spaces. Urban Design Int. 2014, 19, 92-102. [CrossRef]

71. Mikoleit, A.; Pürckhauer, P. Urban Code: 100 Lessons for Understanding the City; The MIT Press: Cambridge, MA, USA, 2011.

72. Palaiologou, G.; Vaughan, L. The Sociability of the Street Interface-Revisiting West Village, Manhattan. In Proceedings of the 21st International Seminar on Urban Form-ISUF, Porto, Portugal, 3-6 July 2014; pp. 88-102.

73. Mavros, P.; Austwick, M.Z.; Smith, A.H. Geo-EEG: Towards the Use of EEG in the Study of Urban Behaviour. Appl. Spat. Anal. Policy 2016, 9, 191-212. [CrossRef]

74. Thwaites, K.; Simpson, J.; Simkins, I. Transitional edges: A conceptual framework for socio-spatial understanding of urban street edges. Urban Design Int. 2020, 25, 295-309. [CrossRef]

75. Stojanovski, T.; Axelsson, O. Typo-Morphology and Environmental Perception of Urban Space. In Proceedings of the XXV International Conference: Urban Form and Social Context: From Traditions to Newest Demands-ISUF, Krasnoyarsk, Russia, 5-9 July 2019; pp. 822-834. 